\title{
«ПИРОЖКИ ДЛЯ БАБУШКИ": КРИТИЧЕСКИЙ ВЗГЛЯД НА ПРОЕКТНОЕ МЫШЛЕНИЕ НКО
}

В фокусе статьи важный аспект процесса «профессионализации» третьего сектора - формирование «проектного мышления». Рассматриваемое явление характерно для членов сообщества третьего сектора, чья деятельность ведется в рамках «проектов»- ограниченной по времени формы деятельности, которая подразумевает строгую последовательность административно-технической организации рабочего процесса. Эмпирическим материалом послужило полевое исследование 16 НКО в Петебурге, занимающихся социальной поддержкой старшего поколения. Однако ключевым кейсом является межрегиональная благотворительная организация, занимающаяся помощью одиноким постояльцам домов престарелых. На основе 30 интервью, включенных наблюдений- посещения домов престарелых, сбора подарков, организации мероприятий, обучения компьютерной грамотности, общению с пожилыми людьми-анализа видеои фотоматериалов, а также внутренних письменных документов, статья предлагает обобщающе-теоретическое обоснование причинам уменьшения возможностей для бенефициаров влиять на процесс принятия решений относительно содержания и процесса социальной поддержки. Используя аналогию с сюжетом сказки про Красную Шапочку, автор предлагает анализ того, как формируется проект, требущий определенных административно-правовых процедур и строгой отчетности. На примере купленных пирогов, привезенных в учреждение долгосрочного ухода с собственной пекарней, показывается конфликт между исполнителями проекта и его руководителями. Кроме того, демонстрируется, как подобный менеджеризм и формализация оказания услуг оказывает негативный эффект на качество услуг, а также на степень их соответствия потребностям постояльцев дома престарелых. Отмечается, что российский кейс проектного мышления

Артур Холявин-магистр (политология), докторант, Университет Хельсинки, Финляндия. Электронная почта: Holavins.A@tsi.lv 
вполне укладывается в мировой тренд профессионализации третьего сектора, подразумевающий отдаление интересов НКО от интересов бенефициаров и увеличение различий между целями и задачами организаций на ценностном уровне. Эти тенденции объясняются потребностями организации в оценке собственной эффективности на практическом уровне, в успешности и способности поддерживать существование, а также обеспечить признание своего «экспертного знания» и административно-технических навыков со стороны других НКО и государства.

Ключевые слова: проектное мышление, НКО, профессионализация, социальная поддержка, организационная логика

DOI: 10.17323/727-0634-2020-18-3-461-474

Сказка о Красной Шапочке повествует о том, как заботливая внучка несет любимой бабушке пирожки, приготовленные матерью. Несмотря на все трудности и преграды, она доставляет гостинцы. Но что если бабушка вовсе не хотела пирожков? В сказке, возможно, пирожки для бабушки действительно являются примером удовлетворения потребностей старшего члена семьи. В реальной жизни, однако, не каждая помощь является востребованной. При этом у получателей заботы не всегда есть возможность сообщить об этом и повлиять на процесс ее оказания (Krause 2014; Eliasoph 2013). Это, в свою очередь, входит в противоречие с идеями об агентности получателей социальной поддержки (Timmermans, Almeling 2009; Kittay, Feder 2003), пациенто-ориентированной медицины (Stewart et al. 2013; Bensing 2000) и «открытой экспертности» в социальной работе (Karvinen-Niinikoski 2016).

В частном случае негосударственной социальной поддержки «объективация» бенефициаров противоречит также ценностям гражданского участия (Eliasoph 2013) и представительства интересов местного сообщества (Jalali 2013; Nagar, Raju 2003). Именно поэтому, казалось бы, отвлеченный вопрос про пирожки из детской сказки может помочь лучше понять то, как функционируют социально ориентированные организации третьего сектора (далеенекоммерческие организации, НКО), в частности процесс их «профессионализации» (Alvarez 2009). Предыдущие исследования свидетельствуют о том, что именно аспекты профессионализации НКО взаимосвязаны с процессом «объективации» бенефициаров третьим сектором. Так, речь идет о возникновении сообщества третьего сектора (Krause 2014), «экспертном знании» (Heyse 2016; Ponte, Cheyns 2013; Covey 1995) и бюрократизации (Markowitz, Tice 2002). Общей характерной чертой для указанных процессов является усложение организационной структуры (Jarvis 2014; Salamon 2001). В случае профессионализированных НКО этот процесс тесно связан с возникновением «проектного мышления»-project thinking (Jalali 2013; Sampson 2002).

Проектное мышление не является специфической чертой третьего сектора. Переход на восприятие любой организованной деятельности через 
призму «проектов»- характерная черта современной управленческой практики (Ajmal, Koskinen 2008; Cicmil et al. 2006). Существует целый пласт экономической и социальной деятельности- обучающие курсы, литература, сообщества, стандарты $I S O$, прививающие эту практику. Можно даже говорить о существовании своеобразной «проектной культуры» (Van Marrewijk 2007; Ruuska 1999). Именно тому, что из себя представляет культура проектного мышления в третьем секторе и к каким организационным изменениям она ведет, посвящена эта статья.

Отправной точкой для обобщающе-теоретической дискуссии является качественное социологическое исследование негосударственной заботы о пожилых в Санкт-Петербурге. Ключевым кейсом является межрегиональная благотворительная организация, занимающаяся помощью одиноким постояльцам домов престарелых. Используя вышеупомянутую аналогию с сюжетной линией сказки про «Красную Шапочку», московский центральный офис и их доноры-это «мама», петербургский филиал (группа активистов, имеющих аффилиацию с фондом) - «Красная Шапочка», а в роли «бабушки» выступают постояльцы домов престарелых. Кейс представляет собой (социальный) проект, требущий определенных административноправовых процедур и строгой отчетности. «Сказочную» аналогию же вызвала одна из форм поддержки- привозимые активистами в учреждение долговременного социального ухода покупные пироги. В данном учреждении есть своя пекарня- и покупные пироги каждый раз оказываются ненужными. Причины, по которым активисты продолжают из раза в раз привозить их рассмотрены далее и как раз связаны с «проектным мышлением».

Кейс «Красной Шапочки» дополняет общемировую теоретическую дискуссию о проектном мышлении среди организаций третьего сектора в двух аспектах. Во-первых, анализируется столкновение проектного мышления с «логикой заботы» (Mol 2008) в рамках одной организации. То есть, речь идет о конфликте между организационной логикой административно-управленческого персонала и сохраняющимся на уровне исполнителей нормативнопрофесиональным мышлением. Последнее может оставаться ориентированным на бенефициаров. Во-вторых, описывается то, как «административно-техническое знание» (Burgman et al. 2011) о ведении проектов сталкивается с профессиональным экспертным знанием медицинских и социальных работников. Наконец, стоит отметить, что описываемый сюжет- наиболее характерный, но далеко не единственный пример того, как сформированные организациями цели проектов и формы услуг петербургских НКО доминируют над некоторыми потребностями людей старшего возраста (бенефициаров).

\section{Проектное мышление в НКО}

Проектное мышление и пренебрежение интересами бенефициаров петербургскими НКО соотносится с примерами деятельности НКО в других 
странах (Scheba, Mustalahti 2015; Banks et al. 2005; Shrestha 2001). Наиболее распространенным объяснением того, почему из-за проектного мышления происходит «объективация» бенефициаров, считается соблюдение строгих формализованных процедур (Brière et al. 2015; Golini et al. 2015). Исследователи утверждают, что это ведет к изменению целей и задач организации в соответствии с бюрократическими требованиями (Hsu, Hasmath 2017; Bayalieva-Jailobaeva 2014).

Так, проектное мышление в организации ведет к крайне негативному восприятию сэкономленных остатков выделенных на проект сумм. С точки зрения низовых потребностей и непроектной деятельности, сэкономленные средства - это благо, пример эффективной деятельности. В рамках проекта неизрасходованные средства - наоборот пример неэффективного планирования и неудачного ведения хозяйственной деятельности. Слишком малые траты- признак того, что весь проект чрезмерно раздут и излишен. Кроме того, это означает, что будущие вливания могут быть меньшев соответствии с произведенными тратами. Наконец, с технической точки зрения финансовые ресурсы не подлежат возрасту по окончанию цикла бухгалтерской отчетности, они уже определены в статью «расходы». И их внезапное появление является поводом для дополнительного аудита и санкций со стороны проверяющих структур.

В целом можно говорить о том, что значительная часть деятельности начинает сводиться к бумажной работе- заполнению форм, отчетов, рамок проектов, грантовых заявок, протоколов совещаний, финансовой и административной документации (Jalali 2013; Wallace 1997). В этом смысле проектное мышление - это форма бюрократизации и усложнения структуры организации. Кроме того, каждый проект имеет формальные критерии успешности. Количественные показатели этих критериев, в конечном счете, становятся индикатором успешности деятельности организации. Кроме того, «оценщиками» от которых зависит будущее являются не бенефициары (получатели социальной поддержки и услуг), а государственные учреждения, крупные частные благотворители, НКО-операторы (посредники). В этом смысле возникновение и развитие «проектного мышления» наглядно отображает весь процесс становления «экспертной» независимости организаций от бенефициаров (Krause 2014).

В рамках данной теоретической парадигмы, проектное мышление находится в конфликте с идеалами низового гражданского участия (Nordb 2017; Choudry, Kapoor 2013; Schade 2005). Во-первых, требования доноров отличаются от потребностей бенефициаров. Во-вторых, взаимодействие с другими организациями формирует профессиональное сообщество, ценностно и идентичностью отдельное от получателей социальной поддержки (Rodriguez 2007). Некоторые исследователи даже сравнивают проектную трансформацию организационной логики с «болезнью»: «projectitis», «проектит» (Nimu 2018; Schade 2005; Lambrou 1997). Горизонт 
планирования «заболевших» организаций сужается до краткосрочной перспективы, социальная поддержка оценивается с точки зрения возможности «повысить осведомленность» (raising awareness) о проблеме у широкой общественности, чтобы обратить внимание заинтересованных сторон (outreaching stakeholders) и обеспечить «усточивость» социальной поддержки (sustainability). Стандартные операционные процедуры выходят на первый план в планировании деятельности НКО. При этом получение финансирования зачастую становится самоцелью (будучи самостоятельным критерием успеха), а бенефициары- своеобразным «товаром», который «продается» донорам (Krause 2014).

Объясняющий механизм столь пессимистичного описания этого типа работы НКО связан с сокращением неформальных практик (Jarvis 2014; Jalali 2013). Согласно новой организационной логике, социальная поддержка сужается до «проектной рамки» (инструмент планирования проекта). Оценка деятельности переносится со сбора обратной связи («фидбэка») со стороны бенефициаров на заранее определенные критерии. Примером хорошего проекта начинает считаться та деятельность, эффект которой можно «посчитать». Индикаторами могут быть количество упоминаний проекта в СМИ, количество проведенных образовательных сессий или, соответственно, число «розданных пирогов». Кроме того, значительные человеческие и временные ресурсы организации начинают занимать обеспечение инфраструктуры проекта (поддержание собственной деятельности), а в конечном счете-выживание и существование самой организации, «operation orientation», т.е. «ориентация на собственную деятельность» (Choudry, Kapoor 2013). Логика руководства третьего сектора проста: если их организация вынужденно прекратит своё существование, то некому будет оказывать социальную поддержку уязвимым социальным группам вовсе. А если так, то проектная культура-вынужденная, но необходимая уступка перед своими изначальными ценностями гражданского участия и субъектности получателей социальной поддержки.

Фактически НКО ничем не обязаны своим бенефициарам. У них нет ни юридических, ни даже моральных обязательств перед ними (т.к. третий сектор лишь дополняет социальную политику, а ответственность, на уровне идеологии, по-прежнему лежит на государстве и семье). Все, чем обладают организации третьего сектора получено от доноров- частных компаний, крупных благотворительных фондов, государства. Поэтому именно перед ними и необходимо отчитываться (Banks et al. 2015: 709). Наконец, технические навыки управления проектами формализованы, структурированы, апеллируют к «рациональному» и направлены на повышение «эффективности» (Burgman et al. 2011). В результате в некоторых случаях проектная логика начинает доминировать над пациенто-ориентированным подходом, и, соответственно, агентность получателей социальной поддержкой вторична. 


\section{Методология исследования}

Статья представляет результаты качественного социологического исследования о «професссионализации» негосударственной заботы о пожилых в Петербурге, проведенном в 2015 г. Проектное мышление не было центральной темой данного исследования. Однако в десяти из 16 исследованных НКО деятельность так или иначе строилась в форме проектов. А категория «проектного мышления» оказалась одной из часто встречающихся при кодировании полуструктурированных интервью с сотрудниками НКО. Стоит отметить, что само кодирование было частично интерпретативным (Miles, Huberman 1994:54-58; Flick 2011: 152-154). То есть часть категорий, включая «проектное мышление», не были аналитически или теоретически детерминированы, а появились непосредственно на этапе анализа эмпирических данных. Проще говоря, «проектное мышление»это тема, которую «подняли» сами участники исследования, а не то, что спрашивал у них я.

Основным источником данных стали включенные наблюдения за планированием и непосредственным оказанием различной социальной помощи людям старшего возраста (пенсионерам). Продолжительные этнографические включенные наблюдения в случае основного анализируемого кейса - благотворительного фонда «Красная Шапочка»- включали этап сбора необходимых вещей для учреждений долговременного социального ухода в сельской местности, а также этап непосредственной заботы о пожилых (передача подарков, организация культурных мерпориятий, общение с постояльцами). Кроме того, в рамках исследования взято 48 полуструктурированных интервью. Тридцать из них записаны с представителями НКО, строящими свою деятельность на основе проектов. Речь идет об организациях-донорах, организациях-посредниках (также «операторы грантовых конкурсов») и организациях-исполнителях - социальных НКО и поставщиках социальных услуг. Так, благотворительный фонд «Красная Шапочка», послуживший основным кейсом для этой статьи, совмещает функции посредника и- на региональном уровне (например, в Петербурге) - исполнителя. Непосредственно с активистами фонда взято три интервью.

Участников исследования можно условно разделить на «организаторов заботы» (менеджеры), «заботящихся» (преподаватели, патронажные работники, социальные работники и т.д.) и «волонтеров». Проектное мышление характерно для первой группы информантов. Однако в том или ином виде о проектах говорили и представители двух других групп информантов, хотя и не всегда в положительном ключе. Зачастую, проектное мышление для них было, наоборот, негативным примером и «оппозицией», на противопоставлении которой формировалась идентичность «заботящегося» как близкого к нуждам и потребностям пожилых людей. 
Дополнительным источником данных послужили официальные и неформальные письменные источники- документы, записи в группе «Вконтакте», фото и видеоматериалы. Использование трех типов и источников данных позволило провести триангуляцию полученных результатов (Kelle 2005).

\section{Кейс: волонтерское движение «Красная Шапочка» и дом престарелых «Бабушкин домик»}

Ниже представлен кейс благотворительного фонда «Красная Шапочка», одной из десяти НКО, ведущих свою деятельность в форме проектов. Центральный офис организации находится в Москве и имеет официальный правовой статус- это официально зарегистрированная некоммерческая организация. Директор организации регулярно посещает профессиональные конференции по старению и участвует во встречах с профильными министерствами. Однако петербургское региональное «отделение» организации юридически не имеет отношения к московской организации. С правовой точки зрения это лишь неформальное объединение людей, состоящих в группе в «Вконтакте». Отношения между центральным офисом и неформальным представительством строятся на том принципе, что активисты- не самостоятельная группа, а «филиал». Однако в отличие от московских сотрудников, петербуржцы не участвуют в ключевых мероприятиях-встречах третьего сектора и не имеют (и не стремятся получить) административно-технических навыков, характерных для профессионализированных НКО.

На практике деятельность петербургских активистов выглядит следующим образом: на постоянной основе собираются пожертвования; затем лидеры группы уточняют у постояльцев, а также медицинского и административного персонала домов престарелых список необходимых вещей. Раз в месяц группа активистов (числом до 20 человек) покупает все в соответствии с составленным списком и отвозит на пункт сбора (частная квартира одного из лидеров группы). Затем активисты отправляются в поездку по нескольким сельским домам престарелых (выезд-рано утром, прибытие домой- поздно вечером того же дня). Так как пожертвований хронически не хватает, они часто обращаются к московскому фонду за дополнительной помощью и те ее выделяют. Поскольку для центрального офиса выделяемые средства-это «проектное финансирование», активистам необходимо отчитываться по всей форме (с частными жертвователями отношения строятся «на честном слове»).

Один из посещаемых домов престарелых- «Бабушкин домик»-сами активисты считают примером «хорошего ухода» за постояльцами. В отличие от других учреждений, здесь есть занятия арт-терапией, неплохая инфраструктура, светлые помещения и отсутствует перегруженность палат. Что важно для описания кейса с точки зрения проблематизации проектного мышления, в «Бабушкином доме» есть собственная пекарня, 
где пекутся хлебобулочные изделия для постояльцев. Ежемесячное посещение дома престарелых начинается со столовой, где директор угощает волонтеров свежими пирожками.

Зная о наличии пекарни, региональная группа никогда по собственной инициативе не покупала бы пироги постояльцам дома престарелых. Но покупные пироги- это составная часть проекта московского офиса. Выполнение его требований является условием предоставления дополнительного финансирования. Поэтому петербургские «Красные Шапочки» вынуждены не только покупать пироги, но также документировать доставку (фотографиями «вручения») и писать про них финансовые и «нарративные» (описательные) отчеты. Естественно, само вручение пирогов не имеет смысла. Так, директор, в очередной раз угощая волонтеров свежими пирогами из собственной пекарни, с улыбкой махнула рукой на покупные: «заберёте домой, детям». И после сделанной фотографии она действительно вернула все купленные пироги обратно активистам.

По условиям проекта пожилым должна быть оказана услуга, которой они и так обеспечены. Причем качество негосударственной услуги даже ниже, чем имеющейся государственной: покупные пироги менее свежие. Однако проектная логика, которой вынуждены подчиняться региональные активисты, не приемлет «полевых» доводов- местного, неэкспертного знания (опыта). С точки зрения проекта, покупка пирогов является неотъемлемой частью стандартного набора подарков постояльцам. Отклониться от прописанной процедуры не представляется возможным: проект финансируется по всей России, и благотворительный фонд не может реагировать на каждый единичный случай, это неэффективно с организационной точки зрения. Отличия в отчетности существенно замедлили бы распределение финансирования. Кроме того, самому фонду было бы трудно объяснить каждое из различий своим донорам, выделившим финансирование на вполне конкретную помощь. К тому же разнообразие сумм открывало бы возможности для коррупции и хищений. Поэтому не отказываться от пирогов в Петербурге-самый простой выход.

Это, в свою очередь, вызывает недовольство со стороны местных активистов. «Красные Шапочки» в Петербурге критически отзываются о московских коллегах «потерявших связь с реальностью» и «работающих ради работы». Свою деятельность они, наоборот, считают-при всей её ограниченности (несколько домов престарелых и пара сотен постояльцев в сравнении с тысячами пожилых, получающих помощь от центрального офиса по всей России) - «лучше»: и эффективней, и нравственней, т.е. соответствующей изначальной цели и задачам организации. Так возникает конфликт между исполнителями и организаторами социальной поддержки. В этом столкновении логик заботы побеждает административноуправленческое крыло НКО. Обладая контролем над финансовыми потоками, они навязывают организационную логику, диктуемую проектным 
мышлением. Возвращаясь к «сказочной» аналогии, Красная Шапочка дарит пироги бабушке, хотя той они совершенно не нужны.

\section{Отчужденные проекты}

Вышеописанный кейс обессмысленной проектной деятельности нагляден, хотя и является своеобразной крайностью. Однако он не единственный в своем роде. Всего из 16 организаций, участвовавших в исследовании, проектное мышление характерно для десяти НКО. В их число входят «инфраструктурные» организации (члены сообщества третьего сектора, помогающие другим НКО, но не оказывающие непосредственную поддержку гражданам), доноры, поставщики социальных услуг, а также некоторые другие социальные НКО.

Важной формой взаимодействия упомянутых десяти организаций (а большинство из них часто и активно сотрудничают друг с другом) являются грантовые конкурсы. Часть организаций (крупные благотворительные фонды) выделяют финансирование. Инфраструктурные НКО занимаются координацией конкурсов. А поставщики социальных услуг и социальные НКО участвуют в этих конкурсах либо в роли партнеровэкспертов, либо непосредственных получателей поддержки. Последняя форма взаимодействия- наиболее строгая из всех возможных форм проектной деятельности. В двухсторонних отношениях НКО неформальные связи в той или иной мере возможны благодаря долгосрочному сотрудничеству и возникновению личных отношений между представителями соответствующих организаций-партнеров. Но в рамках грантового конкурса изначально заявленные цели, задачи и строго определенные критерии формируют крайнюю степень формализации социальной поддержки. Фактически, это негосударственный аналог правовых рамок федеральных законов, также строго регулирующих условия и формы поддержки потенциальным бенефициарам - «социально уязвимым группам».

Следствием формализации является то, что на первый план в грантовом конкурсе выходит не знание потребностей местного сообщества, а «умение написать хороший проект». Кроме того, опыт проектной деятельности всегда является преимуществом, часто- кодифицированным требованием к заявке. Иными словами, навыки проектной деятельности становятся фактором для признания экспертности другими организациями. Поэтому в рамках грантового конкурса наиболее ярко проявляется проектное мышление. Именно в описаниях конкурса, внутренней документации и отчетах встречаются выражения вроде «хорошо написанная заявка», «качественный отчет», «логическая рамка», «повышение осведомленности», «устойчивость социального эффекта»- дискурсивные маркеры такого мышления. Успешное участие в грантовых конкурсах требует выучивания и перенимания соответствующего дискурса и под- 
хода к организационной деятельности. Мик Мур и Шила Стюарт описывают этот процесс следующим образом:

Быстрый рост финансовых ресурсов осложняет работу всех организаций, но особенно НКО [занимающихся вопросами развития]. Их стиль, этос и ценности часто подвергаются существенной угрозе со стороны формальности и бюрократической дисциплины, которые проистекают из такого размера и разнообразия внешнего финансирования <... $>$. Внезапно приоритетом становятся потребности донора, регулярные отчеты, бухгалтерия и соблюдение «контракта» с донором (Moore, Stewart 1998: 83).

В подтверждение приведу пример из интервью участницы исследования (информант 3, проектный менеджер фонда «Жизнь»1), которая отдельно подчеркивала: «[Сами пожилье] подаются на конкурс, но у нас очень строгая схема: программный конкурсный механизм [требования которого они не могут выполнить]». Таким образом, организаторы сознательно выбирают заявку на основе качества написания и потенциального выполнения проекта нежели ее соответствия потребностям сообщества. Формальные критерии и строгость механизма- профессиональные административно-технические стандарты и требования- играют более важную роль для достижения поставленных макро уровневых («устойчивых») целей, нежели удовлетворение конкретных потребностей получателей поддержки (в данном случае-пожилых).

Все проинтервьюированные сотрудники (административного и управленческого уровня) благотворительных фондов, гуманитарных организаций и ресурсных центров придерживаются данной позиции. При этом большинство наемных работников-исполнителей проектов, а также сотрудников, непосредственно взаимодействующих с пожилыми, обычно не поддерживают проектное мышление. Они критикуют его за формализм, подразумевая одновременно и этическую, и практическую составляющую. Несмотря на это исполнители вынуждены подчиняться требованиям проекта и не входят в конфликт с руководством по вопросу взаимодействия с сообществом. Представители «профессиональных сообществ»социальные работники, медсестры, преподаватели- сознательно ограничивают свою экспертность непосредственной исполнительской работой. В результате не только активисты-волонтёры (как в случае «Красной Шапочки»), но и носители альтернативных экспертиз- медицинской, социальной, гериатрической, психологической- подчиняются проектному мышлению своих организаций.

Наконец, в соответствии с теорией о возникновении экспертного сообщества (Rodriguez 2007), многие из опрошенных представителей сообщества профессиональных НКО Петербурга считают умение вести проект одним из необходимых условий принадлежности к гражданскому

\footnotetext{
${ }^{1}$ Из этических соображений все имена и названия в статье изменены (анонимизированы).
} 
обществу. Изначально заявленные в миссиях и иных уставных документах ценности социального блага и помощи уязвимым группам играют вторичную роль. Поэтому общественные и волонтерские движения, низовые инициативы и «группы самопомощи», ведущие свою деятельность иначе нежели в виде проектов, зачастую не признаются представителями петербургского сообщества третьего сектора частью гражданского общества в целом. При этом именно такие организации (в частности, инициативная группа «Красных Шапочек») наиболее близки к местному сообществу.

\section{Заключение}

Эмпирическое исследование НКО, оказывающих социальную поддержку людям старшего возраста в Петербурге, укладывается в теории профессионализации и бюрократизации третьего сектора. Умение «вести проект» действительно является важным прикладным навыком для профессиональных НКО в Петербурге. В результате некоторые организации переформатировали свою деятельность сообразно с требованиями «проектной деятельности». Это подразумевает под собой сокращение перспективы планирования (т.к. проекты имеют четкие временные рамки) и строгое следование формальным процедурам. Сотрудники «профессиональных» НКО в Петербурге получили статус «проектных менеджеров» и освоили административно-технические навыки, связанные с ведением хозяйственной деятельности в соответствии с требованиями проектов.

На примере петербургских кейсов можно говорить, что российские НКО развиваются и изменяются аналогично своим коллегам из других стран. Соответственно, ни социальный, ни политический контексты не играют определяющей роли для формирования «проектного мышления». При этом непосредственные исполнители проекта-как в случае с «Красной Шапочкой»- могут осознавать, что их детельность неэффективна в смысле удовлетворения потребностей бенефициаров. Однако ввиду организационной зависимости от собственного руководства и опосредованно от доноров, они вынуждены подчиняться имеющимся требованиями. Соответственно, организационная логика доминирует над логикой ориентированности на «пациента», агентности бенефициаров и «сотрудничающей модели» принятия решений в социальной работе. Это, в свою очередь, свидетельствует о том, что НКО, занимающиеся социальными вопросами, как и организации из других сфер, постепенно отдаляются от собственных этических установок под давлением внешних факторов. Стоит отметить, что то, насколько данный феномен распространён, и какие инструменты доступны как организациям, так и её сотрудникам, чтобы противостоять негативным эффектам проектного мышления-является темой для дальнейших исследований. 
Arturs Holavins

\title{
LITTLE RED RIDING HOOD AND A CRITIQUE OF 'PROJECT THINKING' AMONG NGOS
}

\begin{abstract}
Based on fieldwork covering sixteen elderly care NGOs in Saint Petersburg (Russia), the article discusses one major aspect in the professionalisation of the third sector, namely, 'project thinking'. A 'project' is a specific form of organising any activity, limited in time and following a strict set of managerial principles and rules. Thus, any NGO, which organises its own work in the form of a project, has to follow very specific requirements to secure financial, material and informational support from donors. 'Project thinking' means a gradual shift among organisations from fulfilling mission-based ethical goals towards self-sustenance and a focus on the formalistic fulfillment of technical and administrative procedures. The key indicative case examined is that of the Little Red Riding Hood volunteer movement, which targets inhabitants of remote rural nursing homes. This permits a discussion of the practical and theoretical implications of formalisation, bureaucratisation and managerialism when organising social care in the form of a project. Also considered is the case of a grocery shop opened in a nursing home equipped with its own bakery. The article discusses project thinking culture and the organisational transformations it entails for the third sector. Specifically, evidence is provided for the objectification of elderly care receivers in terms of neglecting their interests and accessing decision-making over the content and process of care. What is found is that organisational and project goals prevail, leading to the measurement of performance by formal criteria, such as delivery speed, the number of mentions in mass media and the quality of reports. The article also provides evidence of conflict between caregivers and care organisers in terms of understanding 'good care' and the logic of care provision.
\end{abstract}

Keywords: project thinking, NGO, professionalisation, social care, organisational logic

DOI: 10.17323/727-0634-2020-18-3-461-474

\section{References}

Ajmal M. M., Koskinen K. U. (2008) Knowledge Transfer in Project-Based Organizations: An Organizational Culture Perspective. Project Management Journal, 39 (1): 7-15.

Alvarez S.E. (2009) Beyond NGO-ization?: Reflections from Latin America. Development, 52 (2): 175-184.

Banks N., Hulme D., Edwards M. (2015) NGOs, States, and Donors Revisited: Still Too Close for Comfort? World Development, (66): 707-718.

Arturs Holavins-MA Sci. (Pol.), PhD candidate, University of Helsinki, Finland. Email: arturs. holavins@helsinki.fi 
Bayalieva-Jailobaeva K. (2014) A New Look: Professionalization of NGOs in Kyrgyzstan. Central Asian Survey, 33 (3):360-374.

Bensing J. (2000) Bridging the Gap.: The Separate Worlds of Evidence-Based Medicine and Patient-Centered Medicine. Patient education and counseling, 39 (1): 17-25.

Brière S., Proulx D., Flores O. N., Laporte M. (2015) Competencies of Project Managers in International NGOs: Perceptions of Practitioners. International Journal of Project Management, 33 (1): 116-125.

Burgman M.A., McBride M., Ashton R., Speirs-Bridge A., Flander L., Wintle B., Twardy C. (2011) Expert Status and Performance. PLoS One, 6 (7): 1-7.

Choudry A., Kapoor D. (2013) NGOization: Complicity, Contradictions and Prospects. London: Zed Books.

Cicmil S., Williams T., Thomas J., Hodgson D. (2006) Rethinking Project Management: Researching the Actuality of Projects. International Journal of Project Management, 24 (8): 675-686.

Covey J. G. (1995) Accountability and Effectiveness in NGO Policy Alliances. Journal of International Development, (7): 857-868.

Eliasoph N. (2013) Making Volunteers: Civic Life after Welfare's End. Princeton: Princeton University Press.

Flick U. (2011) Introducing Research Methodology: A Beginner's Guide to Doing a Research Project. Washington, D.C.: Sage.

Golini R., Kalchschmidt M., Landoni P. (2015) Adoption of Project Management Practices: The Impact on International Development Projects of Non-governmental Organizations. International Journal of Project Management, 33 (3): 650-663.

Heyse L. (2016) Choosing the Lesser Evil: Understanding Decision Making in Humanitarian Aid NGOs. New York: Routledge.

Hsu J. Y., Hasmath R. (2017) A Maturing Civil Society in China? The Role of Knowledge and Professionalization in the Development of NGOs. China Information, 31 (1): 22-42.

Jalali R. (2013) Financing Empowerment? How Foreign Aid to Southern NGOs and Social Movements Undermines Grass-Roots Mobilization. Sociology Compass, 7 (1): 55-73.

Jarvis D. S. (2014) Policy Transfer, Neo-liberalism or Coercive Institutional Isomorphism? Explaining the Emergence of a Regulatory Regime for Quality Assurance in the Hong Kong Higher Education Sector. Policy and Society, 33 (3): 237-252.

Karvinen-Niinikoski S. (2016) Social Work Supervision: Contributing to Innovative Knowledge Production and Open Expertise. In: N. Could, M. Baldwin (eds.) Social Work, Critical Reflection and the Learning Organization. London: Routledge: 33-50.

Kelle U. (2005) Sociological Explanations between Micro and Macro and the Integration of Qualitative and Quantitative Methods. Historical Social Research/Historische Sozialforschung, 2 (1): 95-117.

Kittay E. F., Feder E. K. (eds.) (2003) The Subject of Care: Feminist Perspectives on Dependency. New York: Rowman \& Littlefield.

Krause M. (2014) The Good Project: Humanitarian Relief NGOs and the Fragmentation of Reason. Chicago: University of Chicago Press.

Lambrou Y. (1997) The Changing Role of NGOs in Rural Chile after Democracy. Bulletin of Latin American Research, 16 (1): 107-116. 
Markowitz L., Tice K. W. (2002) Paradoxes of Professionalization: Parallel Dilemmas in Women's Organizations in the Americas. Gender \& Society, 16 (6): 941-958.

Miles M. B., Huberman A. M. (1994) Qualitative Data Analysis (2 ${ }^{\text {nd }}$ edition). Thousand Oaks: Sage.

Mol A. (2008) The Logic of Care: Health and the Problem of Patient Choice. London: Routledge.

Moore M., Stewart S. (1998) Corporate Governance for NGOs? Development in Practice, 8 (3): 335-342.

Nagar R., Raju S. (2003) Women, NGOs and the Contradictions of Empowerment and Disempowerment: A Conversation. Antipode, 35 (1): 1-13.

Nimu A. (2018) Surviving Mechanisms and Strategies of Gender Equality NGOs in Romania and Poland. VOLUNTAS: International Journal of Voluntary and Nonprofit Organizations, 29 (2): 310-332.

Nordb I. (2017) Indigenous Micro Tourism Businesses, Ethnodevelopment and NGOs: Projectitis in Lago Budi in Chile. In: I.B. de Lima, V. T. King (eds) Tourism and Ethnodevelopment. London: Routledge: 155-169.

Ponte S., Cheyns E. (2013) Voluntary Standards, Expert Knowledge and the Governance of Sustainability Networks. Global Networks, 13 (4):459-477.

Rodriguez D. (2007) The Political Logic of the Non-Profit Industrial Complex. In: Incite! Women of Color Against Violence (eds.) The Revolution Will Not Be Funded: Beyond the Non-Profit Industrial Complex. Durham: Duke University Press:21-40.

Ruuska K. (1999) Projekti hallintaan. Suomen atk-kustannus.

Salamon L. (2001) The Case of America. In: H. K. Anheier, J. Kendall (eds.) Third Sector at the Crossroads. An International Nonprofit Analysis. New York: Routledge: 17-35.

Sampson S. (2002) Weak States, Uncivil Societies and Thousands of NGOs: Benevolent Colonialism in the Balkans. In: B. Törnquist-Plewa, S. Resic (eds.) The Balkans in Focus: Cultural Boundaries in Europe:27-44.

Schade J. (2005) Between Projectitis and the Formation of Countervailing Power-NGOs in Nation-building Processes. In: Hippler J. (ed), Nation Building. A Key Concept for Peaceful Conflict Transformation? London: Pluto Press: 125-136.

Scheba A., Mustalahti I. (2015) Rethinking 'Expert' Knowledge in Community Forest Management in Tanzania. Forest Policy and Economics, (60): 7-18.

Shrestha B. K. (2001) The Sociological Context of (I) NGO Work in Nepal. In: K. B. Bhattachan, T. Viśvavidyālaya, F.E. Stiftung (eds.) NGO, Civil Society and Government in Nepal. Kathmandy: Tribhuvan University:41-62.

Stewart M., Brown J.B., Weston W., McWhinney I. R., McWilliam C. L., Freeman T. (2013) Patient-centered Medicine: Transforming the Clinical Method. Abingdon: CRC Press.

Timmermans S., Almeling R. (2009) Objectification, Standardization, and Commodification in Health Care: A Conceptual Readjustment. Social Science \& Medicine, 69 (1):21-27.

Van Marrewijk A. (2007) Managing Project Culture: The Case of Environ Megaproject. International Journal of Project Management, 25 (3): 290-299.

Wallace T. (1997) New Development Agendas: Changes in UK NGO Policies \& Procedures. Review of African Political Economy, 24 (71):35-55. 